\title{
Efficiency of a novel biodegradable pyrolysis liquid-amended mulch in weed control
}

\section{Hagner, Marleena Maaria}

2020-06

Hagner , M M , Hyvönen , T, Mikola , J , Kemppainen , R , Lindqvist , B , Suojala-Ahlfors , T \& Tiilikkala , K 2020 , ' Efficiency of a novel biodegradable pyrolysis liquid-amended mulch in weed control ' , Weed Research, vol. 60 , no. 3 , pp. 182-193 . https://doi.org/10.1111/wre.12411

http://hdl.handle.net/10138/327714

https://doi.org/10.1111/wre.12411

unspecified

acceptedVersion

Downloaded from Helda, University of Helsinki institutional repository.

This is an electronic reprint of the original article.

This reprint may differ from the original in pagination and typographic detail.

Please cite the original version. 


\section{Efficiency of a novel biodegradable pyrolysis liquid-amended mulch in weed control}

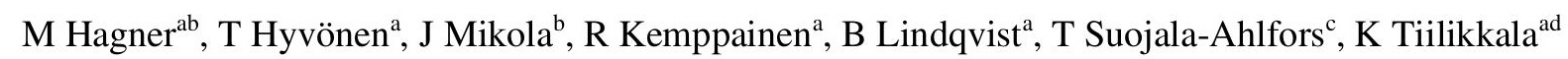

${ }^{a}$ Natural Resources Institute Finland (Luke), FI-31600 Jokioinen, Finland

${ }^{\mathrm{b}}$ University of Helsinki, Faculty of Biological and Environmental Sciences,

Ecosystems and Environment Research Programme, FI-15140 Lahti, Finland

${ }^{\mathrm{c}}$ Natural Resources Institute Finland (Luke), FI-20520 Turku, Finland

${ }^{\mathrm{d}}$ Current address: KT-FinnoServ, FI-33180 Tampere, Finland

*Corresponding author: email: marleena.hagner@luke.fi, tel: +358295323270

Submitted 11 September 2019

Revised version accepted 16 January 2020

Subject Editor: Francesco Tei, University of Perugia, Perugia, Italy

Running head: Novel biodegradable mulch for weed control

\section{Keywords}

Pyrolysis acid, wood vinegar, slow pyrolysis, mulching, weed management

\section{Abstract}

Agrochemicals and plastics represent a burden on natural ecosystems and there is an urgent need to introduce alternative plant protection measures that have fewer negative impacts on the environment. Replacement of plastic mulches and synthetic pesticides with their biodegradable alternatives offers a way to decrease chemical residues. Pyrolysis liquids (PL) have been suggested as easily degradable and residue-free herbicides for agriculture. We tested the efficiency of PL (1-10\% of volume) containing peat mulch (PLM) in weed control under glasshouse and field conditions. We also estimated the length of the withdrawal period needed between PLM spreading and sowing/planting for crops and examined the light permeability and effects of PLM on soil temperature. In the glasshouse, the mulch amended with 5-10\% PL inhibited weed germination entirely. In the agricultural field, the number of weeds remained 44-60\% lower under PLM than under the control mulch. In a study performed in a city park, weed cover around the base of trees remained 64-85\% lower under PLM than without a mulch. However, a 7-21 d withdrawal period, depending on crop plant species, is needed to avoid injuring the crops. PLM inhibited sunlight effectively and the effects on soil heat sum across the growing season remained small. The weed-inhibiting effect of PLM is 
38 probably a result of both the PL compounds and the solid cover, formed by the sticky PL and peat 39 fibers, which acts as a mechanical barrier. We conclude that the PLM is a promising alternative to 40 plastic mulches. 


\section{Introduction}

Industrialization of the agricultural sector has significantly increased the chemical burden on natural ecosystems. Because many pesticides can be harmful to human health and the environment (Alewu \& Nosiri, 2011; Pimentel \& Burgess, 2014; Mnif et al., 2011; Zheng et al., 2016), their use in agriculture is restricted. For instance, in the EU, the Sustainable Use Directive (2009/128/EC) aims at reducing chemical dependence and introducing alternative methods for plant protection. As a consequence, there is a growing interest in introducing non-chemical methods and following the principles of integrated pest management (IPM) (Barzman et al., 2015). As a part of this process, replacement of widely used plastic mulches and synthetic pesticides with biodegradable alternatives offers a way to decrease both plastic (Kasirajan \& Ngouajio, 2012) and pesticide (Tiilikkala et al., 2010) residues in the soil.

Organic materials needed for mulches have been sought from different sources. For instance, Virtanen et al. (2017) reviewed the potential of food industry co-streams as sources of mulching material. New biodegradable and photodegradable plastic films have also been promoted as environmentally friendly options to traditional mulches (Adhikari et al., 2016; Yang et al., 2015). Traditional organic mulches include straw and paper, but these vary in weed control efficiency and are difficult to use (e.g. Cirujeda et al., 2012; Kader et al., 2017). Moreover, few of the biofilms currently available on the market are $100 \%$ bio-based and some contain polymers derived from fossil fuels (petroleum and natural gas), dyes or minerals. Spray coating with sodium alginate (Immirzi et al., 2009) represents another mulching approach and its weed control efficiency seems to be sufficient for at least ornamental shrub cultivation (Giaccone et al., 2018), but overall, further research and development of residue-free nature-based mulches is well justified (Adhikari et al., 2016; Kader et al., 2017).

One promising material for residue-free weed control are the pyrolysis liquids (Hagner, 2013; Hagner et al., 2018). Pyrolysis liquids are by-products of slow pyrolysis, where various biomass materials can be converted at elevated temperatures and in an oxygen-poor atmosphere into fuel gases, chemicals and carbon-rich products (Fagernäs et al., 2012). Pyrolysis liquids have a sticky consistency and can function as a glue between various fibers. After drying, the mixture of pyrolysis liquids and fibers forms a biodegradable cover that is impenetrable to weeds, but permeable to moisture. Earlier studies have shown that pyrolysis liquids can be used as a snail repellent (Lindqvist et al., 2010; Hagner et al., 2018; Tiilikkala et al., 2011) and as a pesticide against insects, bacteria and fungi (Hossain et al., 2015; Ibrahim et al., 2013), but the efficiency of pyrolysis liquid mulch (PLM) in weed control has not been examined even though the mulching technology was recently patented (Finnish patent no. FI127775 (B), international application WO2018108681 (A1)). Potential phytotoxic effects against crop plants also need testing as the damage to crop plants could limit the utility of PLM. 
In the present study, we tested the efficiency of PLM in controlling weeds in the glasshouse and in two different field set-ups. We also examined the potential phytotoxic effects of PLM on the yield of three vegetables - Allium cepa L. (onion), Allium porrum L. (leek) and Lactuca sativa L. (lettuce) and estimated the length of a withdrawal period needed between PLM spreading and sowing or planting of crops. Finally, we recorded soil temperature and the amount of light under the tested mulching materials. We hypothesized that 1) the efficiency of PLM in weed control increases with increasing concentration of pyrolysis liquid (PL),2) the phytotoxic effects on crop plants emerge at higher PL concentrations, but diminish over time, and 3) PLM can effectively inhibit sunlight and has no effect on soil temperature below the mulch.

\section{Materials and methods}

\section{Composition of the mulching material}

The mulching material was composed of peat fibers, hardwood-based slow pyrolysis liquid and tap water. The peat was homogenous, unfertilized white Sphagnum peat (Kekkilä Natural $630 \mathrm{~W}$ ) with a $\mathrm{pH}$ of 5.9 and electrical conductivity (EC) of $27 \mathrm{mS} \mathrm{m}^{-1}$. Two slow pyrolysis liquids (PL) were used: (1) the PL for the glasshouse experiment was produced in willow (Salix sp.) pyrolysis $\left(450^{\circ} \mathrm{C}\right.$, holding time 24 h) according to Fagernäs et al. (2012) in the batch retort A, and (2) the PL for field experiments in birch (Betula sp.) pyrolysis $\left(450^{\circ} \mathrm{C}\right.$, holding time $2 \mathrm{~h}$ ) in the continuous retort $\mathrm{C}$ as described in Fagernäs et al. (2012). During pyrolysis, a composite sample of the total distillate was collected for each liquid and after settling for two weeks, the aqueous and tar fractions were decanted. The aqueous fraction was then used to produce the PLM.

The properties of the two pyrolysis liquids are listed in Table 1 . The titration curves were produced for the liquids by adding $250 \mu \mathrm{L}$ aliquots of either $1 \mathrm{M}$ sodium hydroxide $(\mathrm{NaOH})$ or $1 \mathrm{M}$ hydrochloric acid $(\mathrm{HCl})$ to $10 \mathrm{~mL}$ samples, which were continuously magnetically stirred. The $\mathrm{pH}$ of the solution was recorded after each acid/base addition. Total acidity (sum of acids) was estimated from the initial $\mathrm{pH}$ up to the equivalence point, which in turn was determined by finding the inflection point on the titration curve using a second-derivative method (Table 1).

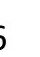


Table1. Characteristics of the slow pyrolysis liquids used in the glasshouse (Willow PL) and field

114 (Birch PL) experiments.

\begin{tabular}{|l|c|c|}
\hline & Willow PL & Birch PL \\
\hline Total acids (\% of liquid volume) & 11.6 & 10.1 \\
\hline Density $\left(\mathrm{g} \mathrm{mL}^{-1}\right)$ & 1.04 & 1.13 \\
\hline Pyrolytic lignin $^{\mathrm{a}}$ (\% of liquid mass) & 0.2 & 4.3 \\
\hline Brix densimetry $^{\mathrm{a}}$ \% of liquid mass) & 31 & 49 \\
\hline${\text { Total organic } \mathrm{C}^{\mathrm{b}} \text { (\% of liquid mass) }}$ & $16.5 \pm 0.6$ & $25.6 \pm 0.1$ \\
\hline Total $\mathrm{N}^{\mathrm{b}}$ (\% of liquid mass) & $0.30 \pm 0.04$ & $0.12 \pm 0.02$ \\
\hline
\end{tabular}

${ }^{a}$ Determined by diluting $1 \mathrm{~mL}$ pyrolysis liquid into $10 \mathrm{~mL} \mathrm{H}_{2} \mathrm{O}$ and recovering the water insoluble

fraction using centrifugation. The aqueous supernatant was analyzed by means of a Brix

Refractiometer to obtain a fraction that represents the total amount of water soluble solutes (Campisi et al., 2016)

${ }^{\mathrm{b}}$ total $\mathrm{N}$ and $\mathrm{C}$ (mean $\pm \mathrm{SD}$ of three samples) were determined using an elemental analyzer (Thermo Scientific, Flash 2000, Organic Elemental Analyzer) and the flash combustion technique (Campisi et al., 2016)

The mulching material was produced by mixing $9 \mathrm{~L}$ of sieved $(2 \mathrm{~mm})$ peat and $10 \mathrm{~L}$ of tap water in a $30 \mathrm{~L}$ bucket using a twist drill (5 min, $300 \mathrm{rpm})$. After mixing, the volume of the final mulching substrate was $10 \mathrm{~L}$. To produce mulches with different PL amendments, various proportions of water were replaced with pyrolysis liquids (see below).

Glasshouse experiment

The glasshouse experiment was carried out in Jokioinen $\left(60^{\circ} 48^{\prime} 15^{\prime \prime} \mathrm{N}, 23^{\circ} 29^{\prime} 10^{\prime \prime} \mathrm{E}\right)$ in spring 2017. For the experiment, field soil $(800 \mathrm{~L})$ was obtained from Mustajoen Multajaloste Ltd. The soil was fine sandy till with 3\% coarse gravel (particle size 6.0-20.0 mm), 3\% fine gravel (2.0-6.0 mm), 7\% coarse sand $(0.6-2.0 \mathrm{~mm}), 19 \%$ sand $(0.2-0.6 \mathrm{~mm}), 33 \%$ fine sand $(0.06-0.2 \mathrm{~mm}), 21 \%$ finer fine sand $(0.02-0.06 \mathrm{~mm}), 10 \%$ silt $(0.002-0.02)$ and $4 \%$ clay $(<0.002 \mathrm{~mm})$. The soil was sieved through a 2$\mathrm{mm}$ sieve, irrigated to $30 \%$ of field capacity and fertilized with Yara Ferticare Kombi to N, P and K levels of 200, 20 and $300 \mathrm{mg} \mathrm{L}^{-1}$, respectively. The sieved soil had a $\mathrm{pH}$ of $6.2, \mathrm{EC}$ of $210 \mathrm{mS} \mathrm{cm}^{-1}$, bulk density of $1090 \mathrm{~g}$ dry matter $\mathrm{L}^{-1}$ and organic matter content of $9.2 \%$ of dry matter. The soil contained on average five seeds of weeds in one liter of soil (mostly Chenopodium album L., Epilobium angustifolium L. and Tripleurospermum inodorum Sch. Bip.).

The experiment consisted of 36 plastic boxes $(420 \times 600 \times 150 \mathrm{~mm})$ that were placed on a table in three rows and 12 columns. Each box was filled with a 100-mm layer of soil (25 L), which was allowed to stabilize for two weeks before the experiment was started. Twenty boxes were used for testing the effects of PLM on lettuce and 16 boxes for testing the effects of PLM on leek. Each box 
consisted of six sowing/planting rows used for different sowing/planting moments and nine or 12 columns of plants (Fig. 1). In the first sowing/planting, 12 lettuce seeds (sowing depth $5 \mathrm{~mm}$ ) and nine leek seedlings ( 5 weeks old, planting depth $20 \mathrm{~mm}$ ) were sown/planted in the first row $30 \mathrm{~mm}$ apart (Fig. 1). Sowing/planting was then repeated weekly for five weeks in other rows (rows being 60 $\mathrm{mm}$ apart). One week after the first sowing/planting (i.e. immediately after finishing the second row), a $250 \times 420 \mathrm{~mm}$ area of soil surface was covered with a $5 \mathrm{~mm}$ thick layer of liquid mulch (equivalent to $600 \mathrm{~mL}$ ) so that six columns of (current or future) plants were surrounded by the PLM (Fig. 1). The mulching treatments included mixed peat and water only (hereafter referred to as control or PLM0) and mixed peat and water with 1,5 or $10 \%(\mathrm{v} / \mathrm{v})$ of water replaced by the pyrolysis liquid (PLM1, PLM5 and PLM10). Each treatment had five (lettuce) or four (leek) replicate boxes, which were assigned to the table to three rows and twelve columns (Fig 1).

Number of weeds in the PLM covered area was counted once a week. Likewise, the viability (dead, weak, viable) of leeks and the germination capability (i.e. the proportion of seeds that germinated), number and survival of germinated lettuces within the PLM covered area were observed weekly. Temperature in the glasshouse was adjusted to $20^{\circ} \mathrm{C}$, the light:dark rhythm was $16: 8 \mathrm{~h}$, and soils were irrigated 2-3 times a week using 0.5-1 L tap water for each box. After four weeks, when all weed seeds were presumably germinated, the weeds were uprooted to ensure that they did not prohibit the growth of crop plants (and overwhelm the effects of PLM) and their fresh mass was measured. Ten weeks after first sowing/planting, all plants growing within the PLM area were uprooted to measure their fresh and dry $\left(70^{\circ} \mathrm{C}, 48 \mathrm{~h}\right)$ biomass. At the harvest, plant age varied from 10 (sowed/planted $7 \mathrm{~d}$ before mulch application) to 5 weeks (sowed/planted $28 \mathrm{~d}$ after application).
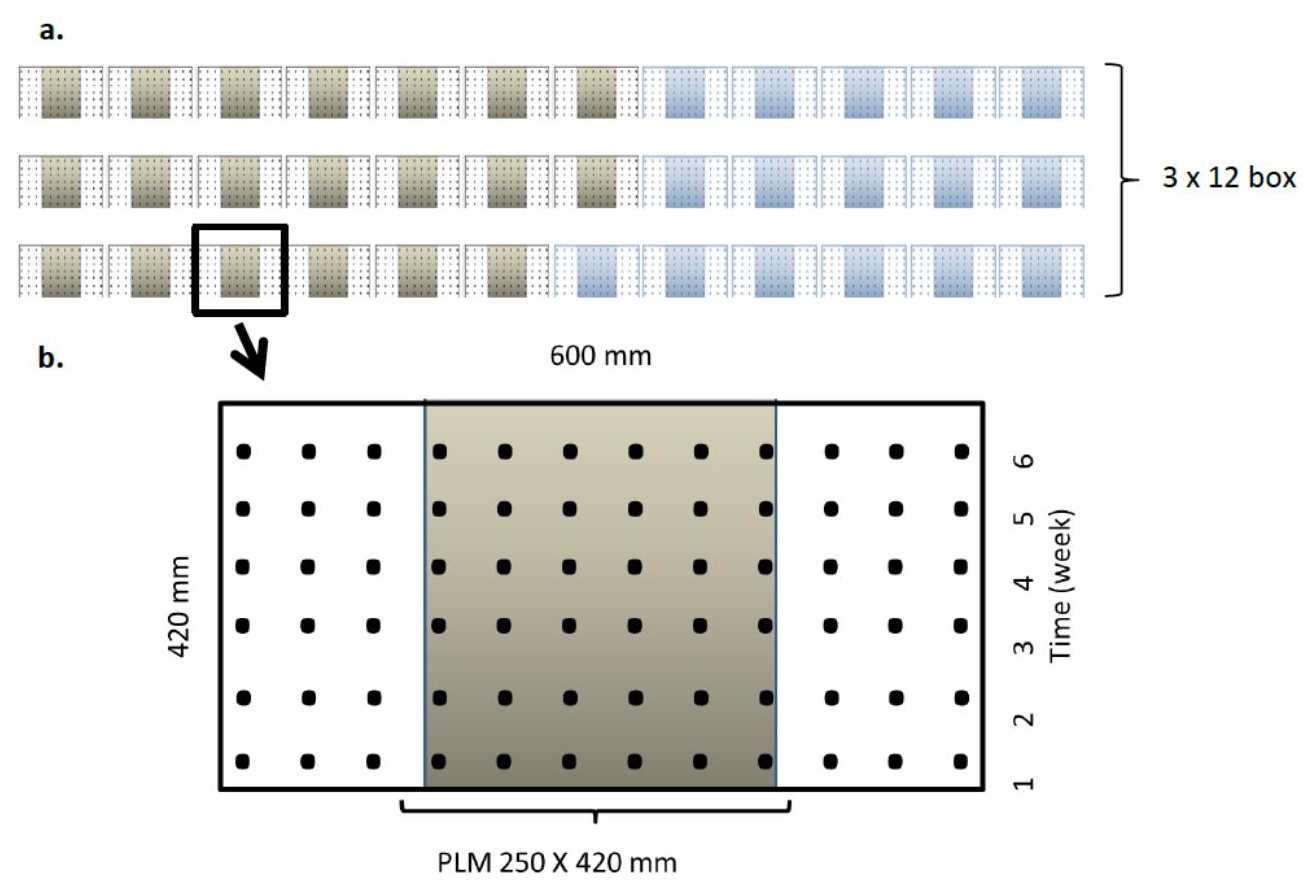
Fig. 1. (a) A glasshouse experiment consisting of 36 plastic boxes $(420 \times 600 \times 150 \mathrm{~mm})$ filled with field soil: 20 boxes (brown) were sown with lettuce (Lactuca sativa) seeds and 16 boxes (blue) planted with leek (Allium porrum) seedlings. (b) Either 12 lettuce seeds or 9 leek seedlings (5 weeks old) were sown/planted in each row $30 \mathrm{~mm}$ apart. Sowing/planting was started at the first row (week 1) and was then repeated at one-week intervals until all rows were sowed/planted. To test the effects of PLM on the crop plants, PLM was applied on the colored area in each box after sowing/planting the second row (week 2). Germination capability and condition of plants were recorded once a week for 10 weeks.

\section{Onion field experiment}

The onion field experiment was established in Piikkiö, South Finland $\left(60^{\circ} 25^{\prime} 30^{\prime \prime} \mathrm{N}, 22^{\circ} 31^{\prime} 00^{\prime \prime} \mathrm{E}\right)$ on 18th of May 2017. The soil in the study site is classified as fine sand with a pH of 6.5 and nutrient contents of Ca 1720, P 22, K 215, Mg 247, S 8, B 0.5, Cu 5.1, Mn 9.6 and Zn $1.95 \mathrm{mg} \mathrm{L}^{-1}$ soil (Finnish standard soil test; Vuorinen \& Mäkitie, 1955). The experimental area was fertilized with a NPK fertilizer (NPK 12-4-17 with macro- and micronutrients, Yara Ltd.) at a rate of $600 \mathrm{~kg} \mathrm{ha}^{-1}$ to provide the plants with $72 \mathrm{~kg} \mathrm{~N}, 24 \mathrm{~kg} \mathrm{P}$ and $102 \mathrm{~kg} \mathrm{~K} \mathrm{ha}^{-1}$, and with a Mn-Ca fertilizer (Yara Ltd.) to balance the micro- and macronutrient status of the soil. During the growing season, $\mathrm{Ca}\left(\mathrm{NO}_{3}\right)_{2}$ was added twice to support the growth of plants with $20 \mathrm{~kg} \mathrm{~N} \mathrm{ha}^{-1}$.

Twenty treatment plots of $1 \times 1 \mathrm{~m}$ area were established with $0.5-\mathrm{m}$ access strips. The randomly assigned treatments included no mulch or a 1-cm layer (equivalent to $10 \mathrm{~L} \mathrm{~m}^{-2}$ ) of mulch amended with water including $0,1.75$ or 3.5\% of PL [hereafter referred to as PLM0 (control), PLM1.75 and PLM3.5] $(\mathrm{n}=5)$. After a 2-week withdrawal period in early June, 15 onion (Allium cepa var. Hylander) seedlings ( 5 weeks old) were planted on each plot $20 \mathrm{~cm}$ apart. The number of weeds in the plots was counted 2, 4, 6, 8, and 10 weeks after mulching. The onions were harvested and their number, quality (index 0-3) and biomass (fresh weight) were recorded after 3.5 months of growth. Four of the plots without mulching were accidentally weeded while the experiment was still running. As the weeds therefore suppressed onion growth more in other plots, the results obtained from weeded plots were excluded from the data and the results of onion biomass without mulching are based on one plot only.

The effects of PLM on soil temperature were evaluated using data loggers (Tinytag Plus2; measurement interval $1 \mathrm{~h}$ ) that were placed in the middle of PLM plots at a depth of $3 \mathrm{~cm}$. Values from these plots were then compared with values obtained under reference plots in the same field, established next to the PLM plots with onion seedlings planted as described above. Three of the reference plots were left without mulching, while the others were covered using either 1) black PEplastic (Raniplast Ltd.; thickness $0.06 \mathrm{~mm}$ ), 2) Walki ${ }^{\circledR}$ Agripap paper (Walki Ltd.) or 3) Bioska Bio Mulch film (Plastiroll Ltd.; thickness $0.015 \mathrm{~mm})(\mathrm{n}=3)$. To characterize the seasonal and diurnal patterns of soil temperatures, monthly mean temperatures were calculated for both midday (12:00- 
15:00) and midnight (00:00-03:00) hours. Soil growing degree days (GDD) were also calculated for each month and for the entire growing season using daily averages and a $5{ }^{\circ} \mathrm{C}$ threshold. Finally, to evaluate the light permeability of PLMs, $0.5 \mathrm{~cm}$ layers of PLM0 and PLM3.5 were spread on plastic Petri dishes ( $\varnothing 21 \mathrm{~cm} ; \mathrm{n}=3$ ). Once the mulch had dried off and formed a disc, the disc was set on the top of a black PVC-tube (height $30 \mathrm{~cm}, \varnothing 20 \mathrm{~cm}$ ), light was directed on to the disc and the photosynthetically active radiation (PAR) that passed through the disc was quantified inside the tube using a LI-COR LI-1000 DataLogger. The amount of PAR measured in the tube without the disc (186 $\mu \mathrm{mol} \mathrm{m} \mathrm{m}^{-2}$ ) was used as a baseline value. The disc was then moistened with $50 \mathrm{~mL}$ water and the quantity of light passing through the disc was measured once again.

\section{City park experiment}

The city park experiment was established in Helsinki, South Finland $\left(60^{\circ} 10^{\prime} 45^{\prime \prime} \mathrm{N}, 24^{\circ} 57^{\prime} 40^{\prime \prime} \mathrm{E}\right)$ on 5th of June 2017. Sixteen lindens (Tilia $\times$ vulgaris, syn. Tilia $\times$ europaea) of various sizes $(\varnothing 15-50 \mathrm{~cm})$ were selected as study trees. The turf growing around the base of the trees (including e.g. Poa pratensis, Festuca rubra, Trifolium repens, Taraxacum officinale) was mulched with PLM0, PLM1.75, PLM3.5 or left without mulching ( $n=3-5)$ (see Supplementary material Fig. 1). Ten liters of PLM was spread around each tree, producing a $25-30 \mathrm{~cm}$ wide and $2-3 \mathrm{~cm}$ thick layer. To estimate the effectiveness of PLM in weed suppress, the areal cover of herbaceous plants was estimated around each tree 4 and 12 weeks later.

\section{Statistical analyses}

In the glasshouse experiment, the effects of mulching (mulch amended with water, mulches amended with water with different concentrations of pyrolysis liquid), sowing/planting time ( $7 \mathrm{~d}$ before- $28 \mathrm{~d}$ after mulching) and monitoring moment (7-35 d after sowing) on the number and biomass of weeds, the biomass and production efficiency of lettuce, and the biomass and proportion of uninjured plants of leek were tested using linear mixed models. The mulching treatment and crop plant species were included in the models as fixed effects, glasshouse table row and column (i.e. the placement of treatment boxes) as random effects, and the sowing/planting time and monitoring time as repeated variables. When the effect of mulching treatment was found to depend on sowing/planting time and/or the monitoring moment, the data were split and the effect of mulching tested separately for each sowing/planting time and monitoring moment using an appropriately simplified mixed model.

In the onion field experiment, the effects of mulching (no mulch, mulch amended with water, mulches amended with water with different concentrations of pyrolysis liquid) and monitoring time on the number of weeds and the number, biomass and quality of onion were tested using ANOVA models, where the mulching treatment was treated as a fixed effect and the monitoring time as a repeated measure. Similar models were used to test the effect of mulching (no mulch, PLM3.5, PEplastic, paper and Bioska) and month on soil temperature, GDD and light level in the onion 
240 experiment as well as in the city park experiment to test the effects of mulching (mulch amended with

241 water, mulches amended with water with different concentrations of pyrolysis liquid) and monitoring

242 time on weed coverage around the base of trees.

243 For ANOVA models, the homogeneity of variances was inspected using a median-based

244 Levene's test and for all models, the normality of model residuals was checked visually using

245 histograms. To fulfill model assumptions, leek biomass and field weed number were log-transformed

246 (the graphs show the original, not back-transformed means). In ANOVA models, the degrees of

247 freedom of F statistics were corrected for repeated measures using Greenhouse-Geisser $\varepsilon$. For mixed

248 models, statistically significant differences among mulching treatment levels were explored using

249 Bonferroni adjusted pair-wise comparisons and for ANOVA using the Student-Newman-Keuls (SNK)

250 post hoc test. All statistical analyses were carried out using the SPSS statistical package (IBM Corp.

251 2016). 


\section{Results}

253

254

255

256

257

258

259

260

261

262

263

264

265

266

267

268

269

270

271

272

\section{Effects on weeds}

Mulches that contained pyrolysis liquid (PLM1-PLM10) reduced the number and biomass of weeds both in the glasshouse and in the field (Fig. 2). In the glasshouse, PLM5 and PLM10 entirely inhibited weed germination (Fig. 2a). Also under PLM1 weed numbers remained 72-80\% lower than under the control mulch PLM0 (Fig. 2a, Table 2a) and the final weed biomass was 66\% lower under PLM1 than PLM0 (16 and $44 \mathrm{~g}$ fresh mass $\mathrm{m}^{-2}$, respectively; Table $2 \mathrm{~b}$ ). The crop plant (lettuce vs. leek) had no effect on the number (Table 2a) or biomass (Table 2b) of weeds (data not shown).

In the onion field experiment, the treatment effect varied with monitoring moment (Fig. 2b, Table 3a). Number of weeds was consistently lower under PLM3.5 than under PLM0 and without treatment, which both supported many weeds and did not differ at any monitoring moment, and the interaction effect is mainly explained by the varying effectiveness of PLM1.75 in relation to PLM0: plots covered with PLM1.75 had significantly fewer weeds than PLM0 plots during weeks 2-6, but not later (Fig. 2b). At the end of the 10-week follow-up period, the number of weeds was 44 and $60 \%$ lower under PLM1.75 and PLM3.5 mulches than under the control mulch, respectively (Fig. 2b).

In the city park experiment, weed cover around the base of trees was on average 80, 94 and 99\% lower at week 4, and 28, 64 and 85\% lower at week 12 under PLM0, PLM1.75 and PLM3.5 mulches, respectively, than around the base of trees without treatment (Fig 2c, Table 3b). Of the mulches, PLM0 and PLM3.5 differed significantly from each other, whereas PLM1.75 did not, either from PLM0 or PLM3.5 (Fig. 2c).
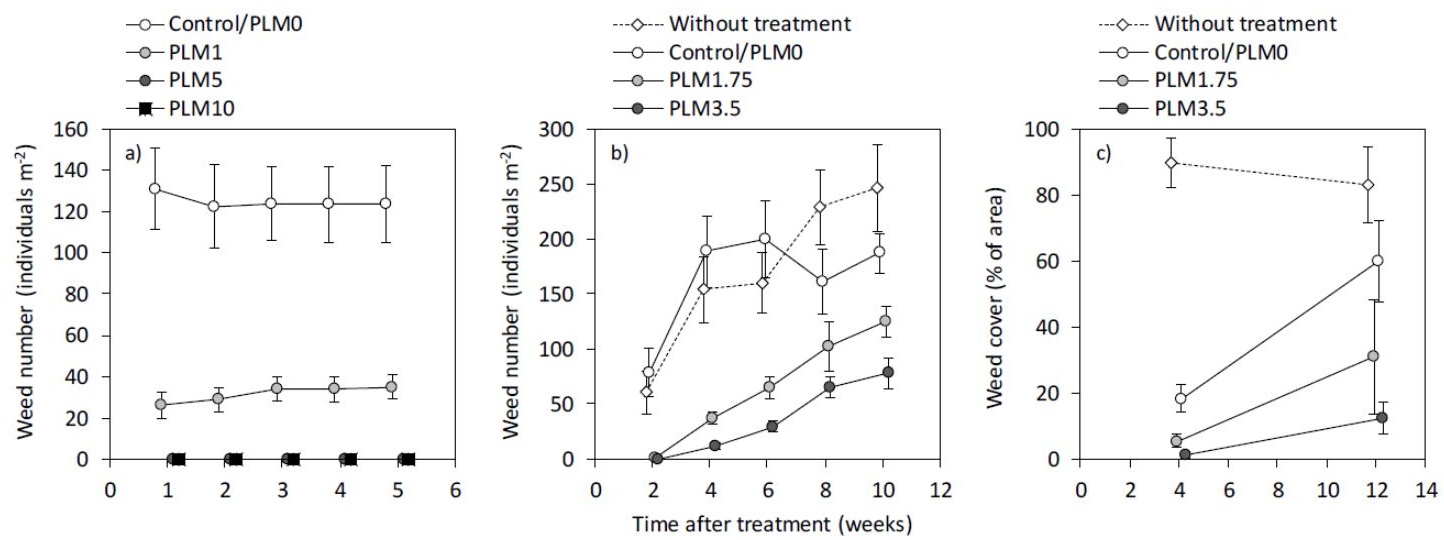

Fig. 2. Number of weeds in a) the glasshouse containers $(n=9$, tests with lettuce and leek combined) and $b)$ onion field plots $(n=5)$, and the areal cover of weeds $c)$ around the base of park trees $(n=3-5)$ when left without a treatment or treated with mulches amended with water containing different concentrations $(0-10 \%)$ of pyrolysis liquid (mean $\pm \mathrm{SE}$ ). 
279 Table 2. Linear mixed model $F$ and $P$ statistics of the effects of $(a-b)$ mulching treatment

280 (Control/PLM0, PLM1), crop plant (lettuce, leek) and monitoring time (1-5 wk) on weed number and

281 biomass, and (c-e) mulching treatment (Control/PLM0, PLM1, PLM5 and PLM10) and

282 sowing/planting time (7 d before-28 d after mulching) on lettuce biomass, leek biomass and

283 percentage of uninjured leeks in the glasshouse experiment (glasshouse table row and column were included in the models as random effects, but are not reported; monitoring time and sowing/planting time were treated as repeated variables; $\mathrm{P}<0.05$ are in bold).

\begin{tabular}{|l|l|l|l|l|}
\hline & Effect $\mathrm{df}$ & Residual df & $\mathrm{F}$ & $\mathrm{P}$ \\
\hline$(\mathrm{a})$ Weed number & & & & \\
\hline Mulching treatment $(\mathrm{M})$ & 1 & 5.7 & 30.4 & $\mathbf{0 . 0 0 2}$ \\
\hline Crop plant $(\mathrm{C})$ & 1 & 9.6 & 0.92 & 0.362 \\
\hline Time of monitoring (T) & 4 & 48 & 0.73 & 0.576 \\
\hline $\mathrm{M} \times \mathrm{C}$ & 1 & 5.7 & 1.07 & 0.344 \\
\hline $\mathrm{M} \times \mathrm{T}$ & 4 & 48 & 2.47 & 0.057 \\
\hline $\mathrm{C} \times \mathrm{T}$ & 4 & 48 & 0.60 & 0.668 \\
\hline $\mathrm{M} \times \mathrm{C} \times \mathrm{T}$ & 4 & 48 & 1.90 & 0.125 \\
\hline & & & & \\
\hline$(\mathrm{b})$ Weed biomass & & & & \\
\hline Mulching treatment $(\mathrm{M})$ & 1 & 5 & 32.6 & $\mathbf{0 . 0 0 2}$ \\
\hline Crop plant $(\mathrm{C})$ & 1 & 9.5 & 0.87 & 0.375 \\
\hline $\mathrm{M} \times \mathrm{C}$ & 1 & 5 & $<0.01$ & 0.987 \\
\hline & & & & \\
\hline$(\mathrm{c})$ Lettuce biomass & & & & \\
\hline Mulching treatment $(\mathrm{M})$ & 3 & 8 & 55.3 & $<\mathbf{0 . 0 0 1}$ \\
\hline Sowing time $(\mathrm{S})$ & 5 & 80 & 28.6 & $<\mathbf{0 . 0 0 1}$ \\
\hline $\mathrm{M} \times \mathrm{S}$ & 15 & 80 & 13.0 & $<\mathbf{0 . 0 0 1}$ \\
\hline & & & & \\
\hline$(\mathrm{d})$ Leek biomass & & & & \\
\hline Mulching treatment $(\mathrm{M})$ & 3 & 9.9 & 1.47 & 0.283 \\
\hline Planting time (P) & 5 & 58.9 & 13.2 & $<\mathbf{0 . 0 0 1}$ \\
\hline $\mathrm{M} \times \mathrm{P}$ & 15 & 58.9 & 0.43 & 0.963 \\
\hline & & & & \\
\hline$(\mathrm{e})$ Percentage of uninjured leeks & & & & \\
\hline Mulching treatment $(\mathrm{M})$ & 3 & 12 & 18.3 & $<\mathbf{0 . 0 0 1}$ \\
\hline Planting time $(\mathrm{P})$ & 5 & 60 & 7.38 & $<\mathbf{0 . 0 0 1}$ \\
\hline $\mathrm{M} \times \mathrm{P}$ & 15 & 60 & 2.89 & $\mathbf{0 . 0 0 2}$ \\
\hline
\end{tabular}

287 Table 3. F and P statistics of ANOVA of the effects of (a) mulching treatment (without mulching, Control/PLM0, PLM1.75, PLM3.5) and monitoring time (2-10 wk after treatment) on weed number in the onion field experiment and (b) mulching treatment (without mulching, Control/PLM0, PLM1.75, PLM3.5) and monitoring time (4 and $12 \mathrm{wk}$ after treatment) on weed coverage around the base of trees in the city park experiment (monitoring time was treated as a repeated measure with

292 Greenhouse-Geisser $\varepsilon$ corrected degrees of freedom; $\mathrm{P}<0.05$ are in bold). 


\begin{tabular}{|l|l|l|l|l|}
\hline & Effect df & Residual df & F & P \\
\hline (a) Weed number in onion field & & & & \\
\hline Mulching treatment $(\mathrm{M})$ & 3 & 15 & 50.2 & $<\mathbf{0 . 0 0 1}$ \\
\hline Time of monitoring (T) & 2.4 & 36.6 & 524 & $<\mathbf{0 . 0 0 1}$ \\
\hline $\mathrm{M} \times \mathrm{T}$ & 7.3 & 36.6 & 62.8 & $<\mathbf{0 . 0 0 1}$ \\
\hline & & & & \\
\hline (b) Weed coverage around park trees & & & & \\
\hline Mulching treatment (M) & 3 & 12 & 20.5 & $<\mathbf{0 . 0 0 1}$ \\
\hline Time of monitoring (T) & 1 & 12 & 8.02 & $\mathbf{0 . 0 1 5}$ \\
\hline $\mathrm{M} \times \mathrm{T}$ & 3 & 12 & 2.23 & 0.138 \\
\hline
\end{tabular}

293

Effects on crop plants in the glasshouse

In the glasshouse, mulching effects on lettuce biomass depended on the sowing time (Fig. 3, Table $2 \mathrm{c})$. When seeds were sown either $7 \mathrm{~d}$ before or on the mulching day, practically no biomass was produced under PLM5 and PLM10, whereas the biomass produced under PLM1 and the control mulch did not differ (Fig. 3). When seeds were sown 7-28 d after mulch application, biomass production was not significantly ( $\mathrm{P}>0.05$ ) affected by the PL content of the mulch (Fig. 3).

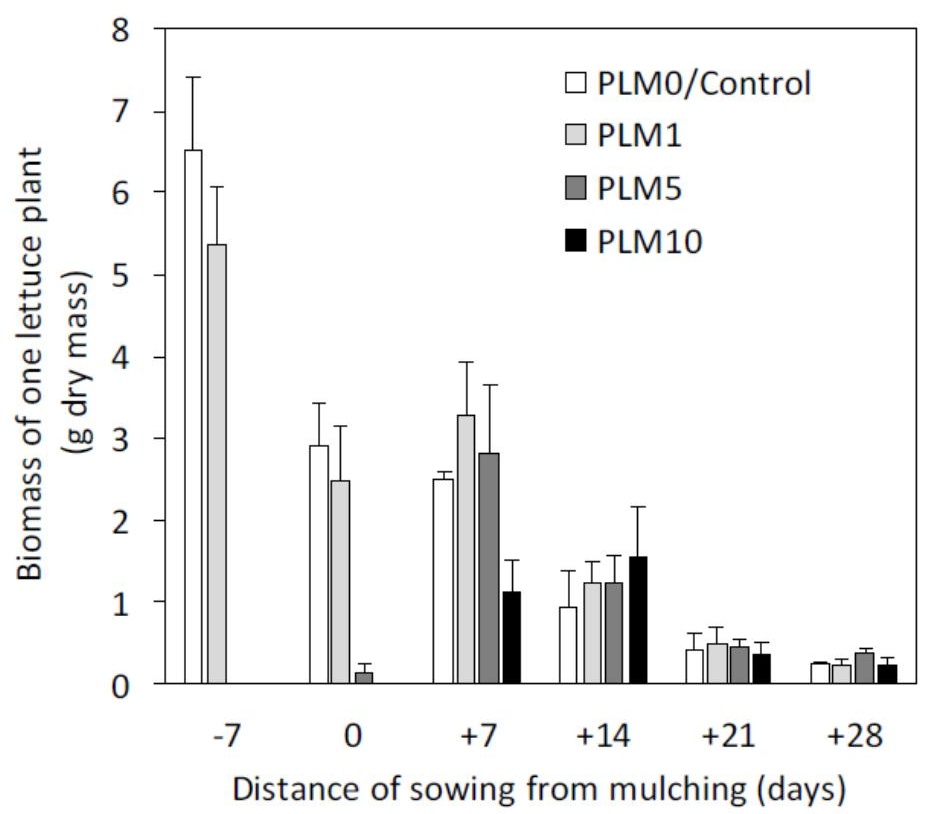

302

Fig. 3. Biomass of single lettuce plants sown in glasshouse containers at different intervals from mulching ( $7 \mathrm{~d}$ before- $28 \mathrm{~d}$ after) and treated with mulches amended with water containing different concentrations $(0-10 \%)$ of pyrolysis liquid (mean + SE, $n=5)$. All plants were harvested ten weeks after first sowing, i.e. at the age of $10-5$ weeks, respectively. 
As with the biomass, mulching effects on the efficiency of lettuce production (the percentage of live plants of the number of sown seeds) depended on sowing time as well as the age of plant under inspection (Fig. 4, Table 4). In those plants, which were sowed $7 \mathrm{~d}$ before mulching (Fig. 4a, Table 4a), treatment effects appeared at the age of $14 \mathrm{~d}$ (i.e. $7 \mathrm{~d}$ after mulching), when plants under PLM5 and PLM10 had for the most part died. At this age, PLM1 and control mulch did not yet differ in effect, but from the age of $21 \mathrm{~d}$, also PLM1 caused a significantly lower production than the control mulch (Fig. 4a). The outcome was similar when seeds were sown on the day of mulch application, except that the effects were apparent already at the age of $7 \mathrm{~d}$ and PLM1 had a stronger negative effect (Fig. 4b, Table 4b). When seeds were sown 7 and $14 \mathrm{~d}$ after mulching, treatment effects appeared at the age of 14 and $21 \mathrm{~d}$, respectively, and in both cases, production was at the end significantly lower under PLM10 than other mulches (Fig. 4c-d, Table 4c-d). Finally, when lettuce seeds were sown 21 or $28 \mathrm{~d}$ after mulch cover, no significant treatment effect was observed on their production at any monitored moment (Fig. 4e-f, Table 4e-f).
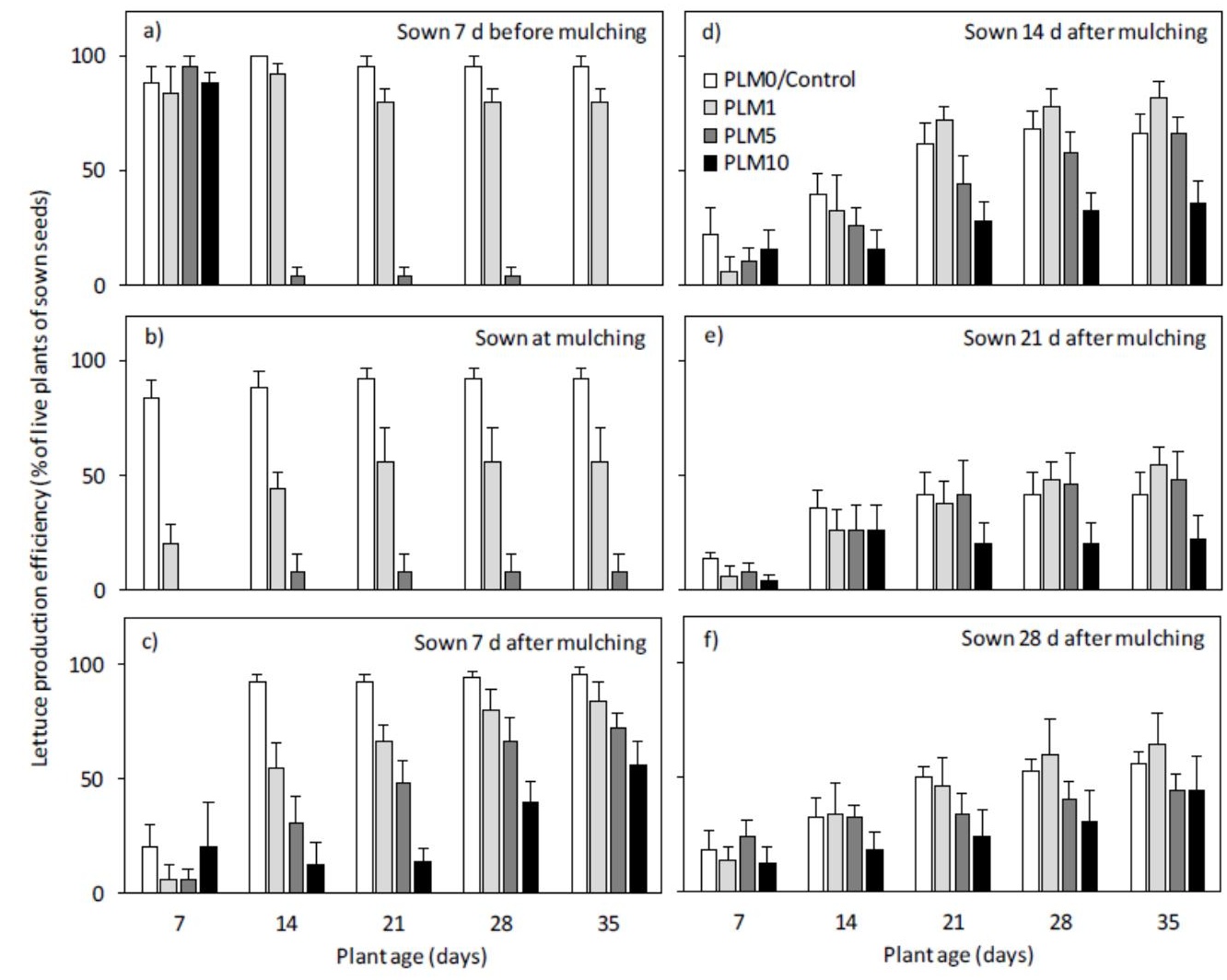

Fig. 4. The efficiency of lettuce production (the percentage of live plants of the number of sown seeds) at different plant age in glasshouse containers when sown at different intervals from mulching ( $7 \mathrm{~d}$ before- $28 \mathrm{~d}$ after) and treated with mulches amended with water containing different concentrations $(0-10 \%)$ of pyrolysis liquid (mean $+\mathrm{SE}, \mathrm{n}=5$ ). 
329 Table 4. Linear mixed model F and P statistics of the effects of mulching (Control/PLM0, PLM1,

330 PLM5 and PLM10) and monitoring age (7, 14, 21, 28 and $35 \mathrm{~d})$ on lettuce production efficiency (the 331 percentage of live plants of the number of sown seeds) in the glasshouse experiment for plants sown 332 at different intervals from mulching ( $7 \mathrm{~d}$ before-28 d after) (glasshouse table row and column were 333 included in the models as random effects, but are not reported; monitoring age was treated as a 334 repeated variable; $\mathrm{P}<0.05$ are in bold).

\begin{tabular}{|l|l|l|l|l|}
\hline & Effect df & Residual df & F & P \\
\hline (a) Sowed 7 d before mulching & & & & \\
\hline Mulching treatment (M) & 3 & 16 & 152 & $<\mathbf{0 . 0 0 1}$ \\
\hline Age when monitored (A) & 4 & 64 & 91.6 & $<\mathbf{0 . 0 0 1}$ \\
\hline M $\times$ A & 12 & 64 & 36.7 & $<\mathbf{0 . 0 0 1}$ \\
\hline & & & & \\
\hline (b) Sowed on the day of mulching & & & & \\
\hline Mulching treatment (M) & 3 & 10.7 & 37.5 & $<\mathbf{0 . 0 0 1}$ \\
\hline Age when monitored (A) & 4 & 64 & 13.3 & $<\mathbf{0 . 0 0 1}$ \\
\hline M $\times$ A & 12 & 64 & 4.97 & $<\mathbf{0 . 0 0 1}$ \\
\hline & & & & \\
\hline (c) Sowed 7 d after mulching & & & & \\
\hline Mulching treatment (M) & 3 & 16 & 10.8 & $<\mathbf{0 . 0 0 1}$ \\
\hline Age when monitored (A) & 4 & 64 & 52.1 & $<\mathbf{0 . 0 0 1}$ \\
\hline M $\times$ A & 12 & 64 & 4.56 & $<\mathbf{0 . 0 0 1}$ \\
\hline & & & & \\
\hline (d) Sowed 14 d after mulching & & & 3.08 & 0.057 \\
\hline Mulching treatment (M) & 3 & 16 & 52.9 & $<\mathbf{0 . 0 0 1}$ \\
\hline Age when monitored (A) & 4 & 64 & 3.35 & $\mathbf{0 . 0 0 1}$ \\
\hline M $\times$ A & 12 & 64 & & \\
\hline & & & & \\
\hline (e) Sowed 21 d after mulching & & & 0.95 & 0.439 \\
\hline Mulching treatment (M) & 3 & 16 & 28.6 & $<\mathbf{0 . 0 0 1}$ \\
\hline Age when monitored (A) & 4 & 64 & 1.84 & 0.060 \\
\hline M $\times$ A & 12 & 64 & & \\
\hline & & & 0.86 & 0.480 \\
\hline (f) Sowed 28 d after mulching & 3 & 64 & 1.53 & 0.139 \\
\hline Mulching treatment (M) & 4 & & & \\
\hline Age when monitored (A) & 12 & 64 & $\mathbf{0 0 1}$ \\
\hline M $\times$ A & & & & \\
\hline & & & & \\
\hline
\end{tabular}

336 Leek biomass was not affected by mulching treatment or mulching $\times$ planting time interaction (Fig.

337 5a, Table 2d). The percentage of uninjured leeks was, in contrast, affected by mulching $\times$ planting time interaction (Fig. 5b, Table 2e). Across all planting moments, the percentage of uninjured individuals was lowest in PLM10 (78\% uninjured), intermediate in PLM5 (85\%) and highest in PLM1 (92\%) and PLM0 (94\%) (Fig. 5b). However, when planting moments were tested separately, PLM10

341 was associated with significantly fewer uninjured individuals than other treatments only when leeks were planted $7 \mathrm{~d}$ before or $7 \mathrm{~d}$ after mulching (Fig. 5b). 

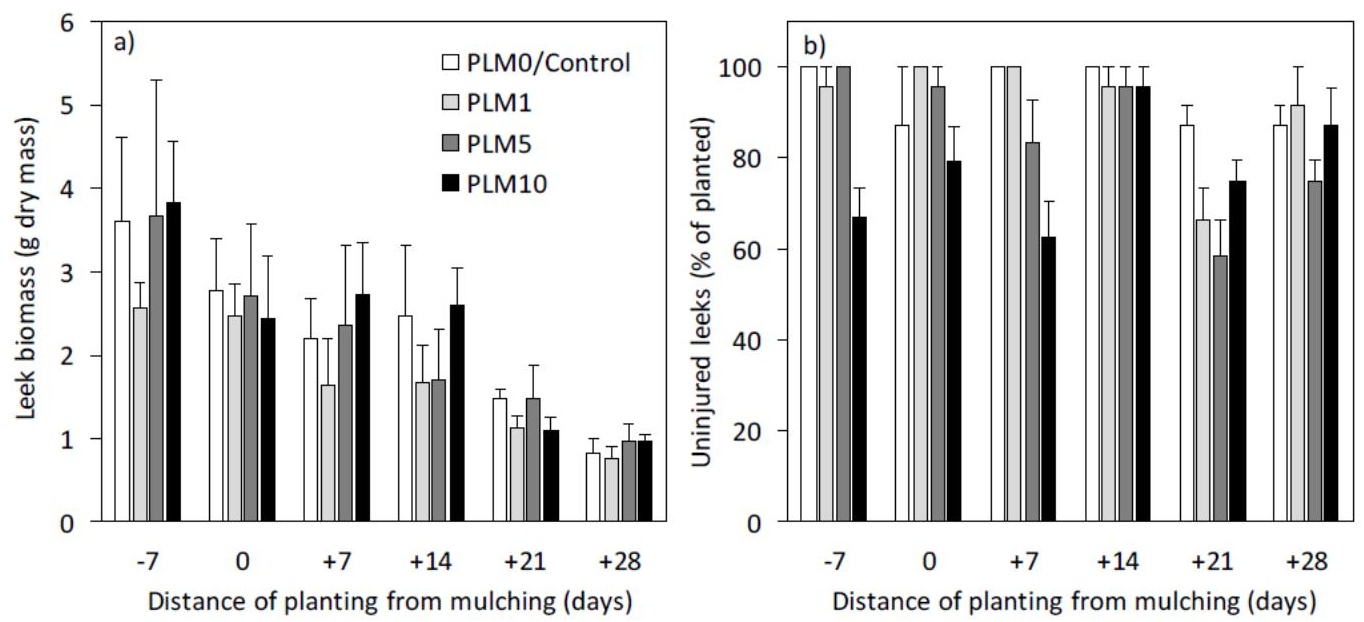

345

346 Fig 5. (a) Leek biomass (per glasshouse container) and (b) proportion of uninjured leeks planted at

347 different intervals from mulching ( $7 \mathrm{~d}$ before- $28 \mathrm{~d}$ after) and treated with mulches amended with

348 water containing different concentrations ( $0-10 \%)$ of pyrolysis liquid (mean $+S E, n=4$ ).

349

350 Effects on crop plants in the field

351 The number of onions harvested at the end of the growing season was not affected by the mulching

352 treatment $\left(\mathrm{F}_{2,12}=0.11, \mathrm{P}=0.899\right)$, whereas the biomass harvested from PLM1.75 and PLM3.5 plots

353 was 1.9- and 2.1-fold, respectively, in comparison to the biomass harvested from PLM0 plots $\left(\mathrm{F}_{2,12}=\right.$

$3545.23, \mathrm{P}=0.023$ ) (Fig 6). The biomass harvested from the single plot without mulching was slightly

355 lower than the mean biomass harvested from PLM0 plots. Proportion of nonviable onions was < $10 \%$

356 in all treatments and no effect on the quality of onions was found (data not shown). 


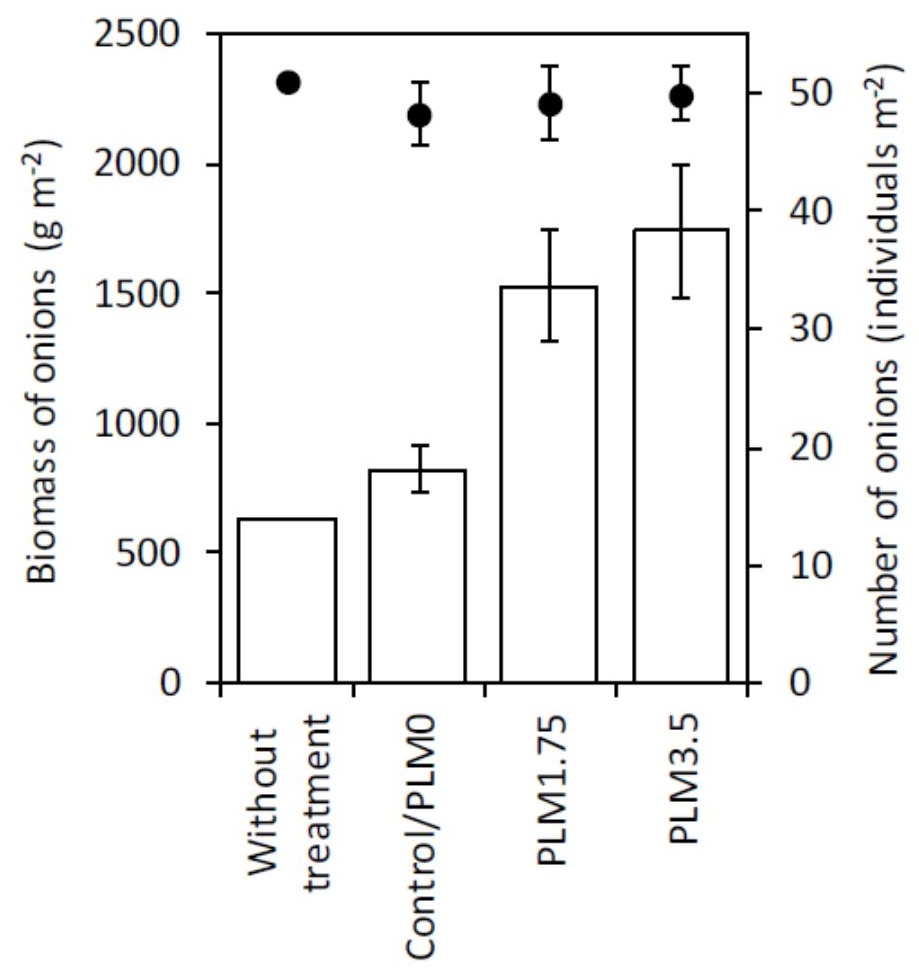

Fig. 6. Number (dots) and biomass (bars) of onions after 3.5 months in field plots covered with mulches amended with water containing different concentrations (0-3.5\%) of pyrolysis liquid (mean $\pm \mathrm{SE}, \mathrm{n}=5$ except for "Without treatment", where $\mathrm{n}=1$ ).

\section{Effects on abiotic factors}

At midday, the soil was on average coldest under PLM3.5 (growing season mean $19.3{ }^{\circ} \mathrm{C}$ ) and warmest without mulching $\left(22.0^{\circ} \mathrm{C}\right)$, but treatment effects also varied significantly along the growing season (Fig. 7, Table 5a). The soil under PLM3.5 was significantly colder than the soil under paper and without mulching in June, colder than the soil under paper, Bioska and without mulching in July, whereas in August no treatment effects appeared (Fig. 7). In contrast to midday measurements, at midnight the soil was on average coldest without mulching (growing season mean $13.3^{\circ} \mathrm{C}$ ) and warmest under PE-plastic $\left(14.4^{\circ} \mathrm{C}\right)$, the soil under PLM3.5 being second warmest $\left(13.7^{\circ} \mathrm{C}\right)$, but again, treatment effects also varied significantly among the months (Fig. 7, Table 5b). The soil under PLM3.5 was warmer than the soil without mulching in June and August and colder than the soil under PE-plastic in July and August (Fig. 7). Soil heat sums did not significantly differ among types of cover when calculated across the entire growing season $\left(\mathrm{F}_{4,10}=1.55, \mathrm{P}=0.262\right)$ (Fig. 8a). When calculated for each month separately, a significant mulching treatment $\times$ month interaction effect appeared (Table 5c): no significant cover type effects appeared in June or August, but in July, the soil under PLM3.5 had 11\% lower heat sum than soil without mulching (Fig. 8b). 

PAR was higher under dry (on average $\left.0.38 \mu \mathrm{mol} \mathrm{m}^{-2} \mathrm{~s}^{-1}\right)$ than moist mulch $\left(0.17 \mu \mathrm{mol} \mathrm{m}^{-2} \mathrm{~s}^{-1}\right)\left(\mathrm{F}_{1,4}=\right.$ 90.5, $\mathrm{P}=0.001$ ), but did not differ between PLM0 (on average 0.41 and $0.17 \mu \mathrm{mol} \mathrm{m}^{-2} \mathrm{~s}^{-1}$ under dry and moist mulch, respectively) and PLM3.5 (0.36 and $\left.0.17 \mu \mathrm{mol} \mathrm{m}^{-2} \mathrm{~s}^{-1}\right) \operatorname{discs}\left(\mathrm{F}_{1,4}=0.23, \mathrm{P}=\right.$ $0.654)$.

384

385

386

387 388

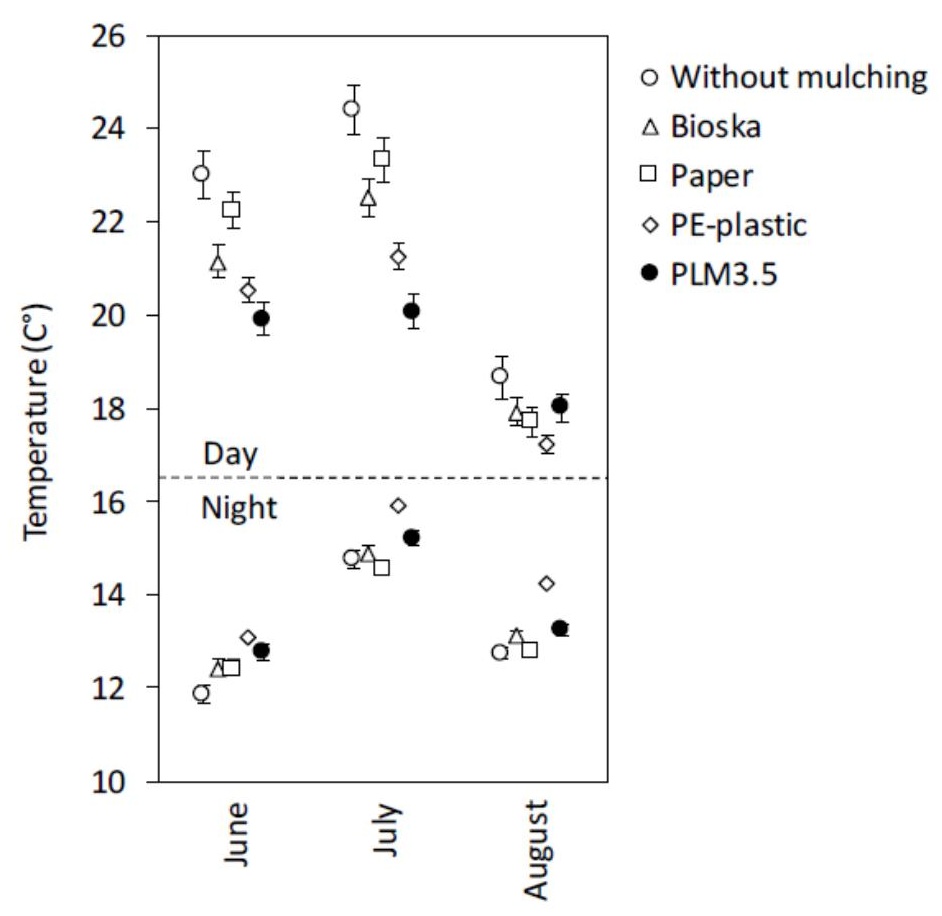

Fig. 7. Monthly mean midday (12:00-15:00) and midnight (00:00-03:00) temperatures $( \pm \mathrm{SE}, \mathrm{n}=3)$ in the soil at $3 \mathrm{~cm}$ depth under different types of mulch in the onion field experiment.
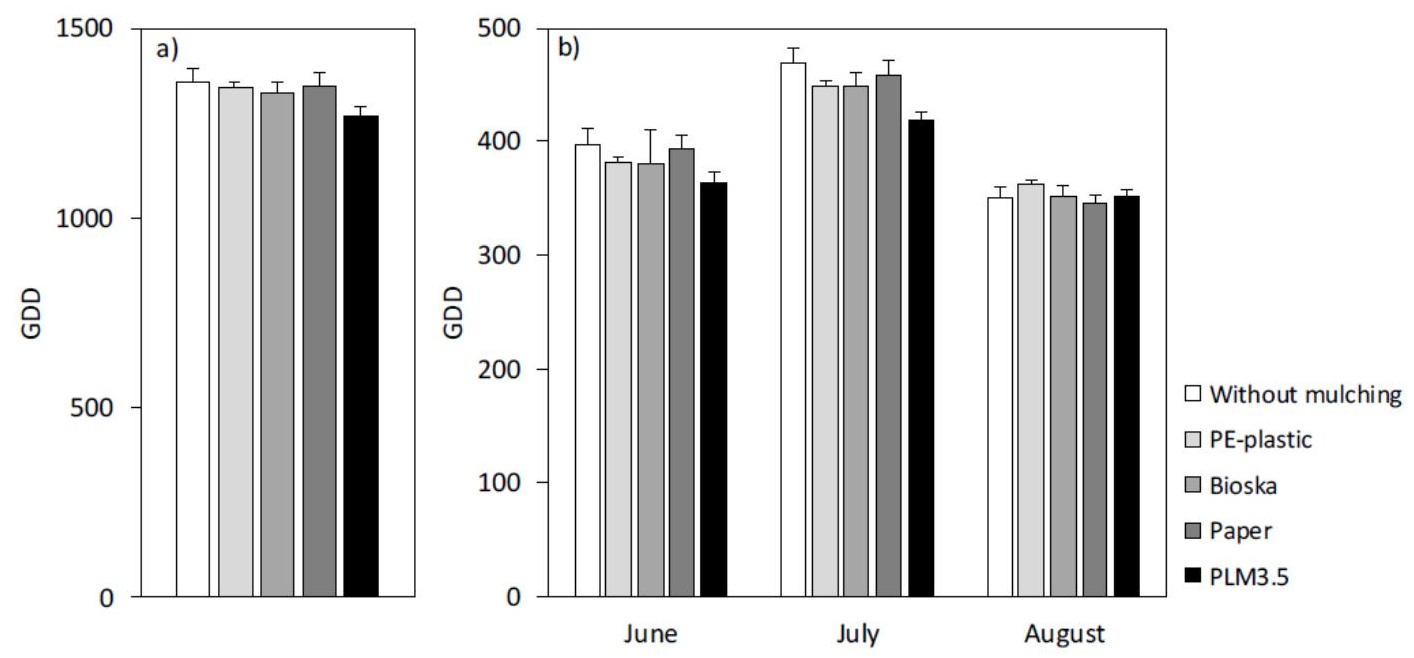
Fig. 8. Heat sum (mean $+\mathrm{SE}, \mathrm{n}=3$ ) as growing degree days (GDD, $5{ }^{\circ} \mathrm{C}$ threshold) in the soil at $3 \mathrm{~cm}$ depth for (a) the whole growing season and (b) June, July and August separately under different types of mulch in the onion field experiment.

Table 5. F and P statistics of ANOVA of the effects of mulching (without mulching, PLM3.5, PEplastic, Bioska, paper) and month (June, July, August) on soil (a) midday temperature, (b) midnight temperature and (c) heat sum (growing degree days GDD with a $5{ }^{\circ} \mathrm{C}$ threshold) in the onion field experiment (month was treated as a repeated measure with Greenhouse-Geisser $\varepsilon$ corrected degrees of freedom; $\mathrm{P}<0.05$ are in bold).

\begin{tabular}{|l|l|l|l|l|}
\hline & Effect df & Residual df & F & P \\
\hline (a) Monthly mean midday temperature & & & & \\
\hline Mulching treatment (Mu) & 4 & 10 & 8.26 & $\mathbf{0 . 0 0 3}$ \\
\hline Month (Mo) & 1.4 & 13.5 & 8370 & $<\mathbf{0 . 0 0 1}$ \\
\hline Mu $\times$ Mo & 5.4 & 13.5 & 189 & $<\mathbf{0 . 0 0 1}$ \\
\hline & & & & \\
\hline (b) Monthly mean midnight temperature & & & & \\
\hline Mulching treatment (Mu) & 4 & 10 & 12.2 & $\mathbf{0 . 0 0 1}$ \\
\hline Month (Mo) & 1.0 & 10.4 & 8714 & $<\mathbf{0 . 0 0 1}$ \\
\hline Mu $\times$ Mo & 4.1 & 10.4 & 36.1 & $<\mathbf{0 . 0 0 1}$ \\
\hline & & & & \\
\hline (c) Soil GDD & & & & \\
\hline Mulching treatment $(\mathrm{Mu})$ & 4 & 10 & 1.38 & 0.310 \\
\hline Month (Mo) & 1.1 & 10.6 & 3050 & $<\mathbf{0 . 0 0 1}$ \\
\hline Mu $\times$ Mo & 4.3 & 10.6 & 30.9 & $<\mathbf{0 . 0 0 1}$ \\
\hline
\end{tabular}

399

\section{Discussion}

We proposed three hypotheses, which were for the most part confirmed. We found that the efficiency of PLM in weed control increased with increasing concentration of PL. We also detected phytotoxic effects on crop plants and that these damages decreased with increasing time since mulching. PLM also effectively inhibited PAR as we expected, but unlike we assumed, PLM decreased soil midday temperatures and increased midnight temperatures in comparison to soils without mulching or soils under more conventional mulches during early and middle growing season. Taken together, these results suggest that PL-amended fiber mulching materials have a potential to be used in weed management programs. A 7-21 d withdrawal period, depending on crop plant species, is however needed to avoid injuring the crops.

As we predicted, the efficiency of PLM on weeds increased with increasing PL concentration and the results from the glasshouse, onion field and city park environments were consistent with each other. Hagner et al. (2018) recently monitored the effectiveness of various slow pyrolysis liquids (pine, forest residues, wheat, willow) against snails, weeds and aphids and suggested that acids, and in particular the acetic acid, were the main reason for the observed pesticidal effects. In addition to the acetic acid, which has long been applied in plant protection as a herbicide (EU 2017, EPA 2017), 
other PL compounds such as furfural, formic acid, valeric acid, propanoic acid and some phenols were also reported to be effective in pest and weed control (Hagner et al., 2018, Hensley \& Burger, 2006; Yatagai et al., 2002). Hence, although the solid cover formed by the sticky PL and peat fibers likely suppressed weed growth by acting as a mechanical obstacle in our study, the weed-inhibiting effect of PLM was most likely also based on the PL compounds.

Our results show that the onion field plots covered with a mulch containing 3.5\% PL had 60\% lower weed abundance than the control plots 10 weeks after mulch application. Around the base of the park trees, the effect was even stronger, the reduction in weed coverage being $85 \%$ after 12 weeks. In the onion field, weed numbers in the PLM area increased over time, possibly due to the wind spreading seeds that fell and rooted in the mulch or due to cracking of PLM that allowed seeds under the mulch to receive light, germinate and grow through the cracks. Similar problems have been reported with other bio-based mulching materials such as starch, cellulose, alginate, chitosan and glucomannan (Adhikari et al., 2016; Briassoulis \& Giannoulis, 2018; Kader et al., 2017). These results suggest that in agricultural fields, PLM is most suitable for controlling weeds under crop plants that are able to cover the soil surface within 1-1.5 months, such as lettuce, cabbages and cucurbits. In the park, a sufficient weed control below tree canopies was achieved already by using mulches with < $3.5 \%$ PL. Regular mowing of lawn possibly reduced the seed production by herbs and grasses in the park and thus facilitated the functioning of PLM. For crop species that need longer weed control, such as onion and leek, additional weeding or further improvement of the PLM is needed. The functioning of PLM could possibly be improved by increasing PL concentration to produce a stronger cover, but this might increase the probability of crop plant damages.

As we expected, phytotoxic effects on crop plants emerged with higher PL concentrations, but also disappeared as time passed after application. It is good to note though that plant growth also decreased with later sowing/planting due to later seedlings being subjected to greater resource competition and weaker growth may have partly restricted the response of seedlings to mulching treatments. Interestingly, PL has earlier shown to either suppress or enhance growth, depending on the dose. For instance, Jun et al. (2006) reported that spraying sufficiently diluted (500-800 times) PL (called bamboo vinegar in their study) on lettuce, cole and cucumber leaves acted as a growth promoter. Similarly, Lei et al. (2018) showed that adding 10000 times diluted PL (termed wood vinegar) increased the root length and dry biomass of cucumber. These authors also regarded PL application at an optimal dilution as a promising soaking agent for seed germination. When the focus is on weed control, applied PL concentrations must be high, however, and the phytotoxic effects on crop plants that we found in our study dominate the PL effects. Our results show that these effects can be severe as shown in the glasshouse experiment with lettuce and PLM5 and PLM10 mulches and apparently, can only be avoided by using a sufficient withdrawal period between mulching and sowing. In the glasshouse experiment, the damaging effects were more severe on lettuce although similar trends were also noted with leek. Lettuce is one of the most sensitive crop species to 
environmental stressors, typically used in phytotoxicity tests (OECD 2003), and therefore PL concentrations with no effect on lettuce should also be safe with other crop plants.

In the field, the number and biomass of onions were not reduced by PLM treatments when a 14 $\mathrm{d}$ withdrawal period and 1.75 and $3.5 \%$ PL concentrations were used in mulching. Instead, the biomass harvested from PLM1.75 and PLM3.5 plots was, on average, twice (1500-1800 $\mathrm{g} \mathrm{m}^{-2}$ ) the biomass harvested from PLM0 plots or plots without mulching. However, weeds were not completely inhibited by PLM1.75 and PLM3.5 treatments and light and nutrient competition by weeds presumably reduced the yield as it remained below a typical yield of $>3000 \mathrm{~g}$ onion $\mathrm{m}^{-2}$ in Finland (Uusitalo et al., 2018). Ecotoxicological risks of PL applied to soil has previously found to be small by Hagner (2013) and pyrolysis oils have recently been classified as readily biodegradable compounds by Campisi et al. (2016). The risks caused by applying a thin layer of PLM with a PL concentration below $3.5 \%$ are therefore likely to be negligible in the soil environment.

Our last prediction was that PLM can effectively inhibit sunlight and has no effect on soil temperature beneath the mulch. As assumed, PLM inhibited light (PAR) effectively both with and without PL and on average only $0.15 \%$ of available PAR was recorded under mulch discs. Comparable values for other biodegradable mulching films, tested in an EC project 'Bioplastics', ranged from 0 to $0.45 \%$ and were for stark-based biodegradable films up to $7.9 \%$ (Adhikari et al., 2016). When we examined soil heat sums across the entire growing season, no differences among the various mulches appeared. However, there was a clear diurnal pattern in early and middle growing season; i.e. soil temperatures below mulches, and in particular under PLM were lower than without mulching at midday and warmer than without mulching at midnight. These findings suggest that PLM can act as an insulation layer and thereby dampen the day-night fluctuation of soil temperatures. Consistent with our results, Moreno and Moreno (2008) reported lower soil temperature under biodegradable film mulch than under traditional polyethylene mulch and Kader (2016) and Haapala et al. (2014) measured lower temperatures under paper mulches than under black plastic mulching or without mulching. It thus appears that light permeability and changes in soil temperature below PLM resemble those under other biodegradable films. Probably due to a cloudy summer, we did not notice the typical increase in soil temperature below a black PE-mulch (Adhikari et al., 2016) at midday, but only during midnight hours. Finally, whether the effects of mulching on soil temperature are beneficial for the growth of crop plants - and also on seed germination and seedling growth of weeds - depends on the climate and plant type. In some regions, farmers should lower and in others increase soil temperatures for a higher yield (Haapala et al., 2014).

Because effective practices for using pyrolysis liquids have not yet been adequately described, well-documented tests are needed to support their utilization. The overall feasibility, environmental sustainability and industrial usability of thermochemical conversion technologies, like slow pyrolysis, depend on whether all produced fractions can be realistically utilized. Currently, liquid and gaseous products are either partly or fully utilized as energy sources at the production site, but fractionating 
the liquids into specific compounds (Zilnik et al., 2012; Rasrendra et al., 2011) and using them as pesticides (Hagner et al., 2018) or for animal slurry acidification (Keskinen et al., 2018) have been suggested. The chemical composition of PLs can vary significantly depending on the feedstock material and production conditions and their effectiveness in weed management might therefore differ significantly. However, it appears that the effectivity of PL in weed control may be predicted based on the acetic acid concentration (Hagner et al., 2018). This suggestion is supported by our current study: although the two PLs used in the glasshouse and field experiments were produced from different feedstock materials by different pyrolysis processes and their chemical content varied, their acetic acid concentrations and effectivity in weed control were comparable.

To conclude, our results suggest that organic materials, like peat, amended with PL can form biodegradable, liquid mulches that offer a possibility to both effectively utilize pyrolysis liquids and replace plastic mulches. Replacing the slowly renewing peat with hemp or other organic renewable components (Adhikari et al., 2016) would further increase the environmental sustainability of PLM. The weed suppressing effect of PLM was highest in the city park, where the weed coverage around the base of trees was reduced by $85 \%$ still 12 weeks after application, being thus comparable to the effect of several commercial herbicides and biodegradable mulches. On the other hand, it appears that achieving similar weed control in agricultural field conditions still requires either improvement in the effectiveness of PLM or supplementary mechanical weeding.

\section{Conflict of Interest}

The authors do not have conflicts of interest.

\section{Source of Funding}

Research has been funded by Business Finland in program 'New business from research ideas' project number 4387/31/2016.

\section{References}

ADHIKARI R, BRISTOW KL, CASEY PS, FREISCHMIDT G, HORNBUCKLE JW \& ADHIKARI B (2016) Preformed and sprayable polymeric mulch film to improve agricultural water use efficiency. Agricultural Water Management 169, 1-13.

ALEWU B \& NOSIRI C (2011) Pesticides and human health. In: Pesticides in the Modern World. (ed. STOYTCHEVA M), InTech, 231-50. Available at: http://www.intechopen.com/books/pesticides-in-the-modern-world-effects-of-pesticidesexposure/pesticide-and-human-health

BARZMAN M, BÀRBERI P, BIRCH ANE et al. (2015) Eight principles of integrated pest management. Agronomy for Sustainable Development 35, 1199-1215. 
BRIASSOULIS D \& GIANNOULIS A (2018) Evaluation of the functionality of bio-based plastic mulching films. Polymer Testing 67, 99-109.

CAMPISI, T, SAMORI C, TORRI C, BARBERA G, FOSCHINI A, KIWAN A GALLETTI P, TAGLIAVINI E \&PASTERIS A (2016) Chemical and ecotoxicological properties of three biooils from pyrolysis of biomasses. Ecotoxicology and Environmental Safety 132, 87-93.

CIRUJEDA A, AIBAR J, ANZALONE Á et al. (2012) Biodegradable mulch instead of polyethylene for weed control of processing tomato production. Agronomy for Sustainable Development 32, 889-897.

EPA (2017) Biopesticides Fact Sheet For Acetic Acid. United States Environmental Protection Agency. Available at: https://www3.epa.gov/pesticides/chem_search/reg_actions/registration/fs_PC-044001_01-Mar01.pdf (8.1.2018)

EU (2017) Pesticides Database. Available at: http://ec.europa.eu/food/plant/pesticides/eu-pesticidesdatabase/public/?event=activesubstance.selection\&language $=\mathrm{EN}$ (8.1.2019)

FAGERNÄS L., KUOPPALA E., TIILIKKALA K \& OASMAA A (2012) Chemical Composition of birch Wood slow pyrolysis products. Energy Fuels 26, 1275-1283.

GIACCONE M, CIRILLO C, SCOGNAMIGLIO P et al. (2018) Biodegradable mulching spray for weed control in the cultivation of containerized ornamental shrubs. Chemical and Biological Technologies in Agriculture 5, 21.

HAAPALA T, PALONEN P, KORPELA A \& AHOKAS J (2014) Feasibility of paper mulches in crop production: a review. Agricultural and Food Science 23, 60-79.

HAGNER M (2013) Potential of slow pyrolysis products birch tar oil, wood vinegar and biochar in sustainable plant protection - pesticidal effects, soil improvement and environmental risks. Academic Dissertation. Reports from the Department of Environmental Sciences, Lahti. Unigrafia. Helsinki, Finland ISBN 978-952-10-9169-8 (pdf)

HAGNER M, TIILIKKALA K, LINDQVIST I et al. (2018) Performance of liquids from slow pyrolysis and hydrothermal carbonization in plant protection. Waste and Biomass Valorization 13, 1-12.

HENSLEY J \& BURGER G (2006) Nematicidal properties of furfural and the development for nematode control in various crops for the United States markets. Journal of Nematology 38, 274274.

HOSSAIN MM, SCOTT MI, MCGARVEY BD et al. (2015) Insecticidal and anti-microbial activity of bio-oil derived from fast pyrolysis of lignin, cellulose, and hemicellulose. Journal of Pest Science 88, 171-179.

IBRAHIM D, KASSIM J, SHEH-HONG L \& RUSLI W (2013) Efficacy of pyroligneous acid from Rhizophora apiculate on pathogenic Candida albicans. Journal of Applied Pharmaceutical Science 3, 7-13. 
IMMIRZI B, SANTAGATA G, VOX G \& SCHETTINI E (2009) Preparation, characterisation and field-testing of a biodegradable sodium alginate-based spray mulch. Biosystem Engineering 102, 461-472.

JUN M, ZHI-MING Y, WEN-QIANG W, QING-LI W (2006) Preliminary study of application effect of bamboo vinegar on vegetable growth. Forest Studies in China 8, 43-47.

KADER MA (2016). Mulching material effects on soil moisture and temperature of soybean (Glycine max) under effective rainfall. Master's thesis. Gifu University, Japan.

KADER MA, SENGE M, MOJID MA \& ITO K (2017) Recent advantages in mulching materials and methods for modifying soil environment. Soil and Tillage Research 168, 155-166.

KASIRAJAN S \& NGOUAJIO M (2012) Polyethylene and biodegradable mulches for agricultural applications: review. Agronomy for Sustainable Development 32, 501-529.

KESKINEN R, HYVÄLUOMA J, WIKBERG H, KÄLLI A, SALO T \& RASA K (2018)

Possibilities of using liquids from slow pyrolysis and hydrothermal carbonization in acidification of animal slurry. Waste and Biomass Valorization 1-5. DOI 10.1007/s12649-017-9910-4

LEI M, LIU B \& WANG X (2018). Effect of adding wood vinegar on cucumber (Cucumis sativus L.) seed germination. IOP Conf. Series: Earth and Environmental Science 128, 012186.

LINDQVIST I, LINDQVIST B, TIILIKKALA K et al. (2010) Birch tar oil is an effective mollusc repellent: field and laboratory experiments using Arianta arbustorum (Gatroboda, Helicidae) and Arion lusitanicus (Gastroboda, Arionidae). Agricultural and Food Science 19, 1-12.

MNIF W, HASSINE AIH, BOUAZIZ A, BARTEGI A, THOMAS O \& ROIG B (2011) Effect of endocrine disruptor pesticides: a review. International Journal of Environmental Research and Public Health 8, 2265-2303.

MORENO MM \& MORENO A (2008) Effect of different biodegradable and polyethylene mulches on soil properties and production in a tomato crop. Scientia Horticulturae 116, 256-263.

OECD (2003) OECD guideline for the testing of chemicals. Terrestrial Plant Test: 208: Seedling Emergence and Seedling Growth Test. 19 p.

PIMENTEL D \& BURGESS M (2014) Environmental and economic costs of the application of pesticides primarily in the United States. In: Integrated Pest Management (eds PIMENTEL D \& PESHIN R) 47-71. New York, Heidelberg, Dordrecht, London: Springer Science + Business Media Dordrecht.

RASRENDRA CB, GIRISUTA B \& VAN DE BOVENKAMP HH (2011) Recovery of acetic acid from an aqueous pyrolysis oil phase by reactive extraction using tri--n--octylamine. Chemical Engineering Journal 176-177, 244-252.

TIILIKKALA K, FAGERNÄS L \& TIILIKKALA J (2010) History and Use of Wood Pyrolysis Liquids as Biocide and Plant Protection Product. The Open Agriculture Journal 4, 111-118. 
TIILIKKALA K, LINDQVIST I, HAGNER M, SETÄLÄ H \& PERDIKIS D (2011) Use of Botanical Pesticides in Modern Plant Protection. In book: Pesticides in the Modern World-Pesticides Use and Management (ed Stoytcheva, M) 259-272. Rijeka, Croatia. InTech.

UUSITALO R, SUOJALA-AHLFORS T, KIVIJÄRVI P \& HURME T. 2018. Yield responses to P fertilization of onion (Allium cepa. L) and cabbage (Brassica oleracea Gapitata Group L.) in Finland. Agricultural and Food Science 27, 63-73.

VIRTANEN S, CHOWREDDY RR, IRMAK S, HONKAPÄÄ K \& ISOM L (2017) Food industry co-streams: potential raw materials for biodegradable mulch film applications. Journal of Polymers and Environment 25, 1110-1130.

VUORINEN J \& MÄKITIE O 1955. The method of soil testing in use in Finland. Agrogeological Publications 63, 1-44.

YANG N. SUN Z, FENG L, ZHENG M \& CHI D (2015) Plastic film mulching for water-efficient agricultural applications and degradable films materials development research. Materials and Manufacturing Process 30, 143-154.

YATAGAI E, NISHIMOTO M, HORI K, OHIRA T \& SHIBATA A (2002) Termiticidal activity of wood vinegar, its components and their homologues. Journal of Wood Science 48, 338-342.

ZHENG S, CHEN B, QIU X, CHEN M, MA Z \& YU X (2016) Distribution and risk assessment of 82 pesticides in Jiulong River and estuary. Chemosphere 144, 1177-1192.

ŽILNIK LF \& JAZBINŠEK A (2012) Recovery of renewable phenolic fraction from pyrolysis oil. Separation and Purificati on Technology 86, 157-170. 